\title{
Administração da diferença, preservação da hegemonia
}

Benjamin Abdala Junior

(Universidade de São Paulo/CNPq)

\begin{abstract}
RESUMO: O ENSAIO DISCUTE QUESTÕES POLÍTICO-CULTURAIS RELATIVAS AO PROCESSO DE GLOBALIZAÇÃO, NESTE MOMENTO DE CRISE DO CAPITALISMO FINANCEIRO E DA IDEOLOGIA NEOLIBERAL. SÃO REATIVADAS POSSÍVEIS SOLUÇÕES ANTICRISES QUE LEVAM À AFIRMAÇÃO - COMO OCORREU A PARTIR DO CRACK DE 1929 - DE TENDÊNCIAS REGULADORAS MAIS DEMOCRÁTICAS, MAS QUE TÊM EM VISTA MUDAR PARADIGMAS PARA PRESERVAR AS FORMULAÇÕES HEGEMÔNICAS. NO CONTRAFLUXO, AS ARTICULAÇÕES COMUNITÁRIAS - COMO O COMUNITARISMO CULTURAL VEICULADO PELA LÍNGUA PORTUGUESA - REÚNEM CONDIÇÕES PARA UMA PARTICIPAÇÃO ATIVA, NO MUNDO QUE SE DESENHA PÓS-NEOLIBERAL.
\end{abstract}

ABSTRACT: THIS ESSAY DISCUSSES POLITICAL AND CULTURAL ISSUES RELATED TO THE GLOBALIZATION PROCESS, IN THIS MOMENT OF FINANCIAL CAPITALISM AND NEOLIBERAL IDEOLOGY CRISIS. IT RECOVERS POSSIBLE ANTI-CRISIS SOLUTIONS THAT LEAD TO THE AFFIRMATION - AS IT HAPPENED FROM THE 1929'S CRACK ON - OF MORE DEMOCRATIC REGULATION TENDENCIES AND THEIR GOALS OF CHANGING PARADIGMS, YET IN ORDER TO PRESERVE HEGEMONIC FORMULATIONS. IN THE CONTRA-FLUX, COMMUNITARIAN ARTICULATIONS - AS THE CULTURAL COMMUNITARISM THROUGH THE PORTUGUESE LANGUAGE - JOIN CONDITIONS TO LEAD TO AN ACTIVE PARTICIPATION, IN A WORLD THAT OUTLINES ITSELF AS A POST-NEO-LIBERAL ONE.

PALAVRAS-CHAVE: COMUNITARISMO CULTURAL - LITERATURA E POLÍTICA - LITERATURAS DE LÍNGUA PORTUGUESA - ADMINISTRAÇÃO DA DIFERENÇA.

KEY-WORDS: CULTURAL COMMUNITARISM - LITERATURE AND POLITICS - LUSOPHONE LITERATURES - ADMINISTRATION OF DIFFERENCE. 
ma atitude paradigmática que marca as tendências literárias empenhadas pode ser traduzida na imagem de que o escritor e o crítico literário precisam ter consciência de onde têm os pés e por onde circulam suas cabeças. Não seria suficiente que eles apenas pudessem ter os pés na terra, como se pretendia nas literaturas inclinadas ao regionalismo ou neo-regionalismo. A circunscrição às linhas de representação da cor local ou da cor humana, conforme já apontou Antonio Candido, constituíram historicamente espartilhos para essas inclinações sinceramente preocupadas com questões de identidade. Desconheciam os regionalistas o fato de que as produções literárias só poderiam ser devidamente consideradas diante do quadro mais amplo das tendências dos campos intelectuais. E, sob esse aspecto, elas não deixariam de estar vinculadas, desde os tempos da expansão européia e mundialização da economia capitalista, à dinâmica e interações dos fluxos culturais, sempre pautados pela assimetria e pela imposição dos padrões hegemônicos.

A diferença procurada pelo regionalismo, em razão desses fluxos, não deixou de ser, então, uma forma de produção literária considerada menor, na hierarquização estabelecida pela divisão internacional do poder simbólico. Mais, o regionalismo não marcou propriamente suas produções com os desejados atributos identitários, que envolveriam predicações e contextualizações mais amplas, mas acabou por se circunscrever aos limites a ela predicados ou consentidos por essa ótica de fora, que julgava desconsiderar, em seu entusiasmo pela cor local. Aceitou, assim, no fundo, uma especialização a ele atribuída que limitava o regional a compartimentos estanques, enquanto a particularidade hegemônica, de matiz eurocêntrica, era inculcada e valorizada como universalizante. A inclinação regional ou neo-regional foi, depois, comutada pelo neo-realismo, que rompeu essa circunscrição, ao procurar uma articulação, que se pretendia dialética, entre o local e um geral, associados à experiência histórica. Essa tendência cultural se formou sob os influxos do campo intelectual originário do front populaire antifascista, dos anos de 1930, e em seus desdobramentos, nos anos subseqüentes, já na atmosfera da polarização ideológica da guerra fria, não se associando a formas de pensar a realidade afins das elites locais.

De forma análoga, poderíamos reafirmar, neste momento histórico de redefinições político-culturais abertas pelo crack financeiro de 2008, que nos parece imprescindível à crítica literária, em sentido virtual e presencial, uma 
consciência sociocultural que tenha correspondência com o desenho neo-realista, isto é, do lugar onde o crítico se situa, que é ao mesmo tempo o lugar de onde ele acessa o mundo. Um ponto de acesso definido, não abstrato, mas articulado à dinâmica de um mundo que se organiza em rede e tende à supranacionalidade. Tais redes inviabilizam propensões localistas, levando a articulações comunitárias de maior poder político. E favorecem articulações em bloco, entre nacionalidades, inclinadas, por sua vez, não a uma universalidade abstrata, mas a um sistema mais amplo, resultante da experiência histórica.

\section{Experiência histórica e fronteiras culturais}

As relações comunitárias supranacionais são, hoje, laços de uma sociedade que tende a se organizar em redes. Em relação aos países de língua portuguesa, esses laços lingüístico-culturais formaram-se através de uma experiência histórica comum, associada ao sistema colonial. Os primeiros colonizadores da América Latina vieram da região, que os árabes chamaram de Al-Ândalus. Algarve provém de Al-Gharb al-Ândalus (Andaluzia Ocidental), que abrangia o atual Algarve e o baixo Alentejo. A maior parte da população popular de Lisboa, na época dos Descobrimentos, some-se a essas constatações, era de origem moura. Eram regiões culturalmente híbridas, para onde confluíram muitas culturas da bacia cultural mediterrânea. Alargando as observações, poderíamos afirmar que a bacia mediterrânica, na perspectiva de um campo que se organiza em rede, constitui um nó multívoco, pelos cruzamentos histórico-culturais entre a Europa, África e Ásia. No processo de colonização das Américas, seu repertório híbrido e polissêmico veio a misturar-se ainda mais pelas interações com os povos ameríndios e africanos. Entendemos que esses países ibero-americanos e, mesmo ibero-afro-americanos, reúnem condições, na atualidade, para a constituição de um bloco comunitário, que, ao lado de outros, mais restritos ou abrangentes, poderão vir a reunir condições de colocar limites às assimetrias imperiais dos fluxos culturais.

Temos argumentado que o mundo configura-se cada vez mais como de fronteiras múltiplas e as identidades devem ser vistas no plural (ABDALA JUNIOR, 2002). Em termos de aproximações lingüístico-culturais, impõem-se horizontes plurilíngües e reciprocidades em termos de poder simbólico. Em 
nosso caso, para além das notórias laçadas para os países de língua espanhola, há a variedade e amplitude das redes comunitárias. Num mundo onde o inglês acabou por se constituir numa espécie de língua franca, é necessário que falemos também em português e outros idiomas, inclusive no campo tecnológico. Em termos lingüísticos, não apenas como língua de cultura, mas de ciência.

Muitas redes comunitárias supranacionais têm-se firmado em escala planetária, como os movimentos de gênero, de defesa e promoção dos direitos humanos, da ecologia etc. Estabelecem-se, assim, campos de interlocução, para além das fronteiras de Estado, de modo a constituir possibilidades de contrapontos à monologia dos fluxos hegemônicos. Tais campos, múltiplos, da vida comunitária supranacional, reúnem condições de contribuir para interferir democraticamente na vida social, numa linha onde a particularidade nacional tende a se articular em rede supranacional. Talvez seja possível continuar a sonhar, como no passado, e tendo em vista um futuro não distante, com a possibilidade de que um trabalhador norte-americano venha a se preocupar com o salário de um outro trabalhador, da América Latina ou da Ásia. É verdade que isso só terá condições de ocorrer a partir da consciência desse trabalhador - a crise é sistêmica, com efeitos globalizadores - de que o salário do outro trabalhador implicará na definição de seu próprio salário. Teríamos assim a possibilidade de uma desejável vinculação entre o comunitário e o social.

\section{Um mundo misturado, reconfigurações}

Neste momento de crack do capitalismo financeiro e de reconfigurações de estratégias, parece-nos imprescindível que a crítica assuma uma atitude mais ativa para criar ou redesenhar, com matização mais forte, tendências de cooperação e solidariedade. E, se possível, fazer confluir, para a interlocução comunitária, bases para a ação política na forma de blocos. Blocos politicamente mais eficazes para estabelecer contrapontos à monologia da competitividade que tem marcado o processo globalizador e que chegou a seu paroxismo, enquanto ideologia dominante à escala planetária, na situação anterior ao crack financeiro.

Entretanto, como diz Riobaldo, personagem de Grande Sertão: Veredas, de Guimarães Rosa, o "mundo é muito misturado", e a personagem fica angus- 
tiada pelo fato de que não divisa a possibilidade de pastos bem demarcados. Busca uma racionalidade binária, como se a razão não envolvesse matizações de todo um feixe de possibilidades:

Careço de que o bom seja bom e o ruim ruim, que dum lado esteja o preto e do outro o branco, que o feio fique bem apartado do bonito e a alegria longe da tristeza! Quero os todos pastos demarcados... Como é que posso com este mundo? A vida é ingrata no macio de si; mas transtraz a esperança mesmo do meio do fel do desespero. Ao que, este mundo é muito misturado... (ROSA, 1986: 191-192)

De forma correlata, se, da economia ao campo cultural, houve efeitos perversos dos modelos articulatórios do capital financeiro, que flexibilizaram fronteiras para impor a ordem hegemônica, por outro lado, o princípio da contradição fez emergir atitudes reativas e esse enfraquecimento favoreceu o fortalecimento de ações comunitárias, pelas brechas dessa política. Nesta nova situação, que se afigura pós-neoliberal - podemos nos permitir o otimismo desta afirmação -, as associações comunitárias tornam-se ainda mais urgentes e envolvem a possibilidade de novas articulações, para além das tradicionais. É de se lembrar a emergência do chamado BRIC - Brasil, Rússia, Índia e China -, entre outras possibilidades, ao lado da revitalização das articulações históricas que o Brasil continua a manter com o bloco europeu, embora tenha se tornado menos expressiva do que antes, em razão da hegemonia norte-americana.

Nessa ampliação, em geral, das interlocuções entre países e blocos, abre-se agora a possibilidade de um melhor diálogo, inclusive em relação aos próprios Estados Unidos, na possível reconfiguração da política desse país. Em nível de Estado, evidentemente os Estados Unidos procurarão estabelecer novas bases, para que continuem a preservar as assimetrias no campo das circulações culturais e de promover a aceitação das formulações discursivas que inculcam e naturalizam seus pressupostos particularistas como universais. $\mathrm{Na}$ nova configuração internacional que se esboça, em meio à crise, surge a possibilidade de uma maior abertura, já que o momento também é de mudança de paradigmas. Isto é, dos escaninhos, em termos de conhecimento, que são as circunscrições pelas quais aprendemos a pensar o mundo. 


\section{Cooperação, reciprocidades}

Em relação à produção literária, esta cada vez mais exige a compreensão do sentido supranacional dos fluxos culturais, com destaque para o comparatismo literário. Foi decorrência histórica, no Brasil, nos estudos de literatura comparada, a afirmação de um comparatismo que veio das imposições de nosso processo de colonização. Verificar essas bases tem sido uma forma de nos situar diante dos fluxos inclinados à colonização de nosso imaginário. Trata-se de um comparatismo importante e necessário para o nosso autoconhecimento. Nas atitudes de atores culturais do passado podem ser configuradas linhas que são imprescindíveis para a melhor compreensão de nossa atualidade sociocultural. Entretanto, a restrição a esse comparatismo não nos parece suficiente, em termos político-culturais. Temos proposto uma outra forma de comparatismo, para figurar ao lado desse primeiro, que com ele acaba por se imbricar na prática comparatista. Um comparatismo prospectivo, pautado por relações comunitárias, um comparatismo da solidariedade, da cooperação. Comparar diante de problemáticas que nos envolvem a todos para nos conhecer naquilo que temos de próprio e em comum. Enlaces comparatistas, tendentes a relações de reciprocidade.

É evidente que qualquer novo recorte que implique ações de ordem política poderá fazer emergir novas formas de hegemonia. Mesmo quando nos empolgamos com o estabelecimento de laços de cooperação, é preciso atentar para hábitos culturais arraigados, que incorporam gestos hegemônicos nas relações entre países e regiões, em situações de aparente reciprocidade. Lembramos, para ilustrar, um comentário do crítico cubano Roberto Fernández Retamar (1995), que afirmava gostar de alguns críticos europeus que, de maneira simpática, diziam que o Caribe era o Mediterrâneo americano, mas que ficaria muito mais satisfeito se eles viessem também a dizer, imaginamos, sem constrangimentos, que o Mediterrâneo é que seria o Caribe europeu...

O processo colonial fixou hábitos, repertórios literários e culturais, que vieram dessa experiência histórica e dos contatos culturais entre povos que até então não se conheciam. Se há hoje toda uma inclinação crítica para mudanças de paradigmas, sejam eles filosóficos ou estéticos, em relação às áreas do conhecimento, entendemos que essa tendência não pode se naturalizar sobre um rótulo genérico de um "pós", uma redução ao obsoleto de toda 
uma experiência que se consubstancia no presente. Pior ainda pode ocorrer em relação às instâncias políticas, onde o "pós", afeito às condições da mídia e dos produtos moda, procura tudo reduzir a uma tábula rasa, sem passado. A experiência histórica e suas realizações passam a ser situadas como um repertório passivo, para a estilização sem história, formas restritas a uma espécie de "estado de dicionário", referência a um conhecido poema de Drummond. "Freqüentar o mundo das palavras", como é de se verificar mais adiante, na voz desse mesmo poeta, implica conhecer o processo que as modelou.

\section{Pós-colonialismos}

Temos de levar na devida consideração o fato de que a teorização pós-colonial tem discutido convenientemente questões relativas à globalização, aos deslocamentos dos povos e ao processo de americanização do mundo, sob o impacto da mídia e do consumo mercadológico. Em relação às questões político-sociais, entretanto, ela às vezes pode tender a generalizações abstratas. A uma perspectiva desavisada, podem ser igualmente pós-coloniais quaisquer sociedades marcadas pelo colonialismo, sem maior consideração sobre sua historicidade, nivelando países que se emanciparam no período pós-Segunda Guerra Mundial, aos que se emanciparam desde o século XIX. Falar de pós-colonialismo, sem consciência dessas especificidades, implica nivelar uma cultura como a do Canadá, ou da África do Sul, por exemplo, à complexa situação cultural da Índia - ambas ex-colônias britânicas. Só uma análise sociocultural do processo histórico pode revelar de que pós-colonialismo se trata. Essa situação se torna ainda mais complexa, se vinculada - como acontece - à ênfase diaspórica dos estudos pós-coloniais. Coloca-se novamente a necessidade de se considerar de onde fala o crítico e os laços socioculturais que acabam por enredar suas formulações discursivas de um sentido político.

Como se observa na bem humorada, mas irônica, observação de Retamar, as linhas de construção do imaginário associado a um campo intelectual, enquanto forma, continuam a atuar para além da situação de origem. São atualizadas muitas vezes com marcas do poder simbólico hegemônico, que vem de situações históricas específicas e que não podem ser escamoteadas. $\mathrm{O}$ pensamento crítico não pode descartar, através de um prefixo "pós", cinco 
séculos de contatos e assimetrias culturais, inclusive o repertório cultural que foi construído. O grande problema, voltando-nos ao conceito de pós-colonialismo, é de que ele pode levar a atenuar o que é fundamental ao ato crítico: uma visão crítica e atuante, capaz de problematizar fatos histórico-culturais, que vieram de experiências históricas que têm suas particularidades.

São muitos os pós-colonialismos. Há, por exemplo, o pós-colonialismo do ex-colonizador, que encontramos num romance como Os cus de judas, de Lobo Antunes (1979); e, para contrastar, o do ex-colonizado, como em Mayombe, de Pepetela (1982). O primeiro vai desconstruir mitos e fazer de sua memória individual um depoimento que se quer história. Pepetela, numa direção oposta, embala-se por mitos, sem deixar de criticar indivíduos que se querem mitos. Nessa crítica, evidencia posturas etnocêntricas do passado que se reproduzem no presente. Em Lobo Antunes, enfatiza-se a desconstrução dos mitos e a distopia; em Pepetela, na formação de um novo Estado nacional, a construção e a utopia. Há ainda o pós-colonialismo dos colonizadores radicados ou que retornaram à metrópole e dos ex-colonizados que para lá migraram. A clara delimitação do chamado lócus enunciativo e de sua historicidade parece-nos, pois, imprescindível para uma crítica que pretenda afastarse da generalidade e repercutir politicamente.

\section{Mimetismo cultural e relações de poder}

Refletir sobre especificidades nacionais implica situá-las num processo de agenciamentos comunitários que tem um solo histórico e relações de poder simbólico. Temos destacado o sentido político de se discutir literatura no âmbito do comunitarismo ibero-afro-americano, mas - voltamos a insistir - as articulações comunitárias podem ser de muitas ordens e politicamente nos parece importante relevar que o mundo atual é de fronteiras múltiplas e identidades plurais, seja numa perspectiva individual ou nacional. São interações que levam à consideração de um complexo cultural híbrido, interativo, onde a cultura brasileira, por exemplo, é multifacetada e se alimenta produtivamente de pedaços de muitas culturas, sem deixar de sofrer os efeitos das assimetrias dos fluxos culturais. Tais considerações, para além das especificidades nacionais, torna necessária a consideração do repertório enfaticamente híbrido de 
nossa formação cultural. Na apropriação desse repertório, a consciência dessa historicidade e relações de poder que ensejou, pode contribuir para o afastamento de produções miméticas, afins da convenção ou do estereótipo. E esse sentido crítico contribui para o desenvolvimento de inclinações abertas à criatividade e que às vezes acabam para o questionamento de espartilhos ideológicos e identidades míticas. Foi o que ocorreu, por exemplo, com o poema "Camões: história, coração, linguagem", de Carlos Drummond de Andrade. Escrito numa situação histórica pós-Revolução dos Cravos, o poema mostra apropriação de imagens e procedimentos poéticos camonianas. Estabelece um diálogo entre marcas da historicidade das leituras de Camões e a da nova situação histórica, democrática, de Portugal:

Dos heróis que cantaste, que restou

senão a melodia do teu canto?

As armas em ferrugem se desfazem, os barões nos jazigos dizem nada.

(Apud ABDALA JUNIOR, 1993: 62)

Nessa desideologização das apreensões conservadoras, em especial da época salazarista, sem deixar de seguir imagens e ritmos camonianos, o poeta brasileiro termina por afirmar:

Luís, homem estranho, que pelo verbo

és, mais que amador, o próprio amor

latejante, esquecido, revoltado, submisso, renascente, reflorindo

em cem mil corações multiplicado.

És a linguagem. Dor particular

deixa de existir para fazer-se

dor de todos os homens, musical,

na voz de órfico acento, peregrina.

A identificação no repertório comum não implica, assim, mimetismo. A distância crítica advém não apenas através da perspectiva de um brasileiro, mas sobretudo de quem estabelece suas bases poéticas na persistência de 
uma mesma linguagem comunitária. Ampliando essas observações, podemos afirmar que são importantes do ponto de vista crítico estudar esses diálogos, embutidos - explicitamente ou não - nos repertórios literários, que circulam entre os países de língua portuguesa. Por outro lado, relevar as relações de poder que envolvem essa circulação é uma forma de se afastar da celebração, seja da mimese ou de um pretenso sincretismo ou do hibridismo, que desconsidera as relações de poder e encaminha atitudes assimilacionistas tendentes à cultura do colonizador e suas implicações no que tange à cooptação política. Não se pode, entretanto, deixar de considerar devidamente - para além das referências individualizadas como a de Camões - o fato de que a plasticidade da língua literária portuguesa constituir-se um processo de modelização que vem desde sua formação nos tempos medievais.

\section{Além da cor da pele}

À flexibilidade da circulação dos produtos culturais, ao ritmo nômade do capital financeiro, que se articula em rede, sempre reduzindo distâncias por velocidade, sempre desdobrável, parece-nos importante contrapor estratégicas contra-hegemônicas, associadas aos comunitarismos supranacionais. Esse processo vertiginoso de estandardização dos produtos culturais, por parte da economia de mercado, não se restringe à estandardização de massa. Convém não nos esquecermos de que a hegemonia possui bases amplas, que não deixam de ser mercadológicas, e procura incorporar em suas redes até mesmo a contestação de seu próprio sistema. Trata-se da perspectiva da administração da diferença, que temos insistido em apontar. A diferença como administração política e abertura de nicho de mercado.

Noutro sentido, esta incorporação pode contribuir para a dinamização do sistema: mudar para que as coisas continuem estruturalmente as mesmas. Ou, como aparece no livro/filme O leopardo, de Giuseppe Lampedusa/Luchino Visconti, "É preciso que algumas coisas mudem, para que tudo continue na mesma”. A emergência parcial do novo, sob controle político-social das estruturas pré-estabelecidas e que faz valer sua hegemonia para controlá-lo, ao mesmo tempo em que se beneficia de sues influxos para atualizar suas redes numa nova configuração histórica. 
Não há, entretanto, para a crítica empenhada, como fugir dessa situação, sob pena de fechar o seu campo de reflexões em perspectivas isolacionistas. Impõem-se ao crítico que ele entre nessas águas, cuidando para não perder a direção de seu projeto e ser cooptado pelo aparente nomadismo dos fluxos, que afinal se mostram sempre confluentes para as bases hegemônicas. Esta é uma questão política, que se imbrica em rede com a vida sociocultural. Para tanto, tendo em vista a necessidade de uma atitude prospectiva, conforme temos enfatizado, o crítico não pode se limitar exclusivamente a atitudes de negatividade crítica, embora esta não deixe de ser sempre um seu contraponto imprescindível. Do ponto de vista político, entendemos que fundamentalmente deve se embalar por uma espécie de otimismo crítico, para dar continuidade, sob novas formas, a gestos, que vieram do passado, com atores imbuídos da esperança de que a vida social poderia ser melhor do que é. Observe-se, nesse sentido, o seguinte fragmento do poema "Coração em África", do são-tomense Francisco José Tenreiro, que temos reiteradamente apontado quando discutimos a circulação cultural do campo intelectual do após-Guerra, tal como ocorreu nos horizontes ibero-afro-americanos e na atmosfera da guerra fria:

[...] de coração em África com as mãos e os pés trambolhos disformes e deformados como os quadros de Portinari dos estivadores do mar e dos meninos ranhosos viciados pelas olheiras fundas das gomas de Pomar vou cogitando na pretidão do mundo que ultrapassa a própria cor da pele dos homens brancos amarelos negros [...]. (ANDRADE \& TENREIRO, 1982: 68)

Tenreiro é um dos atores do campo intelectual dos anos de 1950, para quem "a pretidão do mundo [...] ultrapassa a própria cor da pele dos homens brancos amarelos negros". Seu poema ilustra não apenas o comunitarismo cultural que se faz pela ibero-afro-américa. Noutras passagens - é um poema longo -, aponta para atitudes libertárias de personalidades negras da África, Caribe e Estados Unidos. É diante dessa afirmação, que sentimo-nos tentados a contextualizar com o momento político atual. A eleição de Barack Obama foi seguramente um golpe no conservadorismo norte-americano que se afirmou desde os tempos do macartismo, à revelia dos princípios estabelecidos na carta da ONU de 1946. Não há dúvida de que seu triunfo representa a ascensão da tendência liberal 
democrática por sobre a prepotência imperial dos últimos tempos, quando se torna imprescindível se voltar às perspectivas sociais de um Estado regulador. Há, não obstante, limites para esse otimismo.

Se Barack Obama escreveu um livro como $A$ audácia da esperança (OBAMA, 2007), que em parte pode estar comprometido com o que Edward Said chamou de o "outro EUA", as circunstâncias de sua eleição, isto é, suas bases políticas e econômicas associadas às elites desse país, impõem barreiras a essa "ousadia". A mídia vem proclamando um renascimento norte-americano (inclusive através da voz do próprio Obama), isto é, um renascimento do "espírito americano", tradicional discurso dessas elites. Estamos muito longe de um "renascimento negro", para matizar nosso discurso pela referência à designação do movimento a que se ligou o poeta Langston Hughes. Mais distantes ainda, em sentido amplo - já que a pretidão do mundo "ultrapassa a cor da pele" -, de um renascimento dos excluídos não apenas negros, mas também brancos, amarelos e mestiços. Mestiços, aliás, como o próprio Obama, que só é negro pela marcação ideológica e racista ainda dominante nos EUA, mesmo para aqueles que dizem "tolerar" a diferença.

\section{Multiculturalismo e eurocentrismo}

Neste momento que se afigura em processo pós-neoliberal, a afirmação de uma tendência mais tolerante, que procura valer-se da estratégia de administrar da diferença, afim, por exemplo, de uma vertente multiculturalista de matização liberal (ver SHOT e STAM, 2006), pode constituir uma maneira mais inteligente e de longo prazo de se preservar e mesmo promover a hegemonia. Estratégia para um capitalismo administrado, um retorno, em nossas bases, dos princípios norteadores do governo Roosevelt. Seria uma espécie de um novo New Deal, de onde - já que as coisas são misturadas - foi possível surgir, não obstante, a obra de um Caldwell, Hemingway, Dos Passos, Gold, Steinbeck, Faulkner etc. E também a organização das Nações Unidas e da carta que estabelecia o princípio da autodeterminação dos povos.

$\mathrm{O}$ discurso de respeito à diferença, que agora se afirma é o da perspectiva liberal do multiculturalismo, que pode tender à guetização dos excluídos, ou à simples tolerância dos incluídos administrados. O pensamento hegemônico 
norte-americano tem sido avesso à valorização das misturas. O puritanismo religioso que vem dos tempos coloniais e sua práxis histórica levaram à afirmação ideológica da imagem de um mundo onde a mistura foi vista como degradação. Na grande narrativa da formação nacional desse país, inculcada mundialmente pela mídia, em especial de Hollywood, a missão civilizatória se fez inicialmente contra os que consideravam bárbaros indígenas. Pouco importa as poucas escaramuças dos nativos contra o invasor europeu, da história real, pois quase sempre eles se limitaram a se afastar dos invasores, quando expulsos de suas terras mais férteis. Para essa mídia ideológica, os nativos eram impostores em suas próprias terras e estas eram como se fossem vazias - a "Terra Prometida" ou "Nova Canaã" da simbologia que vem das cruzadas. E a estrutura dessa narrativa fundamentalista, associada ao poder imperial, vem até nossos dias, comutando indígenas por negros, latino-americanos, asiáticos ou árabes. Estes são os "outros" (na designação naturalizada, os "étnicos”), sempre mostrados como agressivos, indisciplinados, incivilizados etc. Afinam-se, nessa perspectiva ideológica, como mestiços, impuros.

Tal eurocentrismo norte-americano pode vir a ser agora atenuado, na nova configuração que se esboça. Fala-se insistentemente na necessidade de "tolerância": tolerância liberal, uma nova modalidade dos pressupostos de caridade, uma via de mão única, sem reciprocidade. A aproximação dos excluídos, que foi uma das bases fortes da eleição de Obama e que fez a diferença, não é evidentemente relevada. Para além dessa modulação da tolerância, é imprescindível ao pensamento crítico descortinar também as relações de poder envolvidas. Sem a discussão dessas relações, o discurso multicultural que, ao que parece, deve se afirmar ainda mais, não deixará de ser um veículo conceitual de administração da diferença, tendo em vista a manutenção da hegemonia norte-americana, vale dizer, de suas elites. Falta a esse multiculturalismo de tintas liberais a consideração de vozes simultâneas em tensão, uma espécie de um áspero concerto polifônico construído pelas diferenças. Logo, uma perspectiva crítica capaz de contraditar formulações discursivas hegemônicas, tendentes ao nivelamento de uma espécie de "branqueamento" eurocêntrico.

Em relação aos países ibero-afro-americanos, ao contrário do que tem ocorrido nos EUA, onde o hibridismo é escamoteado, a intelectualidade tem visto na diversidade étnica um fator de originalidade e criatividade. A estratégia das elites "crioulas" tem sido outra: exaltar a integração, sempre tendente 
ao branqueamento, mascarando a estratificação social, como ocorreu com Gilberto Freyre, entre outros. Nos primeiros contatos, como aparece em Partes de Africa, de Helder Macedo, na carta de "achamento" do Brasil, Pero Vaz de Caminha, diante da nudez dos índios, leva a entender que se deve "vestir a inocência, ensinar esses homens e mulheres os rudimentos da fé cristã". E declara: "a essa gente não lhes falece outra cousa para ser toda cristã que entenderem-nos". Fluxo único, sem reciprocidade. Ironicamente, para a inculcação dos seus altos valores lá deixam, "desde logo, dois degredados - dois criminosos - foram incumbidos de iniciar essa piedosa tarefa, para o "acrescentamento de nossa santa fé" (MACEDO, 1991: 164).

A consciência crítica de Helder Macedo certamente se evidencia, a partir de seu lócus enunciativo: tem vivido entre fronteiras, e, ao mesmo tempo, estreitamente vinculado ao comunitarismo lingüístico-cultural da língua portuguesa. Observa relevos, contornos, contradições, no que era, antes, monologia discursiva. A preocupação de Caminha pela vestimenta, curiosamente, teve um corolário posterior, reverso, quando da Inquisição: esta, ao contrário dos seguidores de Vieira, estava mais preocupada simbolicamente com o fato de os colonizadores tirarem suas vestimentas, afastando-se dos fundamentalismos religiosos da Contra-Reforma. Descobrir, nesse sentido, significa tirar as roupas para revelar a natureza humana, que constitui, aliás, uma das estratégias discursivas de Helder Macedo em sua narrativa. Curiosamente, voltando-nos à evidência do mundo misturado, Caminha parece se encantar com as "vergonhas" das índias, usando o trocadilho de que elas não tinham nenhuma vergonha de naturalmente as mostrar aos olhos dos portugueses. Este princípio da contradição já é um esboço de arte literária. Diz mais e de forma mais densa das contradições e da situação psicossocial dos futuros colonizadores, do que o relato meramente informativo, que estava a descoberto na "carta do achamento".

\section{A administração da diferença}

Reiteramos, pois, no contraponto ao que naturalizou na atmosfera de concretização utópica do capitalismo financeiro, e seus modos de articulação, que o acesso à rede supranacional se faz num lócus enunciativo determinado 
e ele é fundamental para a crítica. Se na vida universitária, por exemplo, um docente situa-se numa universidade norte-americana, ele não pode desconsiderar o fato de que seu discurso pode estar associado a estratégias hegemônicas desse país. Faz parte do consenso hegemônico, na atualidade, não apenas aceitar, mas promover a capitalização da diferença. Uma diferença que se consubstancia em produtos, desde o da imagem democrática do país hegemônico até a mercadorias mais explicitamente comercializáveis. Não se pode esquecer a posição dos Estados Unidos como único país a defender a inserção da cultura como "produto", na Organização Mundial do Comércio. Para além do produto diretamente comercializável, a hegemonia implica um "reconhecimento" internacional da instituição onde esse crítico trabalha, o que certamente atrairá alunos e docentes, inclusive dos países não-hegemônicos. A partir dessa situação, serão criadas condições para convênios interinstitucionais com esses países, tendentes à preservação da hegemonia. Só uma efetiva reciprocidade entre os atores da comunidade universitária envolvida poderá atenuar essas assimetrias. Isto é, a consciência da dimensão política que envolve a pesquisa científica. A busca da "eficácia", aparentemente neutra, pode mascarar o sentido de hegemônico do poder simbólico.

É provável que o fluxo cultural hegemônico, configurado, nos estudos literários, em teorias e correntes críticas, acabe por estabelecer no país um entreposto associado. Se esse porto receptivo for efetivamente crítico, é de se presumir que veiculará fluxos de natureza diferente daqueles da estandardização que norteia a cultura de massa, mas não deixará de apresentar vetorização equivalente. Sem reconfigurações das redes discursivas intervenientes nas dinâmicas contra-hegemônicas, o novo lócus pode ser um porto que corre o risco de ser no máximo uma particularidade de um desenho mais abrangente da administração da diferença. O núcleo determinante da enunciação, que imprime a direção do fluxo, no caso da sublocação subalterna, não deixa de estar no centro hegemônico. É próprio das estratégias de legitimação da hegemonia tolerar a diferença, desde que seja uma diferença administrada, quase sempre prevista e elaborada, enquanto possibilidade de abertura, desde o centro do fluxo. Tais observações valem tanto para o vestuário quanto para as modas críticas. Através de estratégias de convergência dessa modalidade de administração, a incorporação orgânica da diferença poderá inclusive constituir fator de dinamização da rede hegemônica. Mudar, assim, para continuar a 
colonizar o imaginário, determinando padrões e condicionando expectativas que enredam o mundo das margens.

Os atores de um campo intelectual supranacional - situem-se nas esferas do centro ou nas margens (há as margens dos centros e os centros das margens) -, que se pretenderem efetivamente críticos, não podem ignorar as relações de pertencimento desses sujeitos. São laços que levam à vida sociocultural e que não podem ser escamoteados, em função da própria objetividade da crítica. Mesmo quando se adotem atitudes como se estivessem em situações psicossociais de migrantes - esta é uma das tópicas dos Estudos Culturais -, o diálogo não se faz em abstrato, mas com culturas diferentes, provenientes de experiências históricas que têm singularidades e motivações políticas. E estar nos Estados Unidos não é como estar no Brasil ou em qualquer outra parte do planeta, como aparece em certos discursos tendentes à neutralização da diferença e à sublocação do mesmo. Se os óculos críticos advindos dessa circulação cultural podem aguçar a percepção, pela caracterização dos relevos dissonantes das culturas em contato, em função da própria criticidade eles não podem implicar convergências óticas inclinadas à neutralização, tendo em vista a preservação da hegemonia dos fluxos orientados para a continuada colonização do imaginário nas regiões ou países situados na periferia do capital.

É motivo recorrente, que historicamente tem envolvido o processo de colonização das margens, o relevo de considerações acríticas, dissociadas da situação sociocultural e, sobretudo, de atualidade histórica. Nesse sentido, o crítico não pode se ater à performance narcisista, que seria própria de quem está (apenas) de passagem, e também na apologia de um aparente descompromisso, afinado com o hiperindividualismo da situação que resultou no crack financeiro. Uma situação - é verdade -, que não deixa de apresentar analogias com a dos assim chamados "anos loucos" da década de 1920. Ao adotar posturas afins de uma espécie de relativismo nômade, ele acaba por se limitar a resvalar nos obstáculos, sem manter laços situacionais para além do efêmero do discurso da moda. No fundo, essas atitudes - à revelia da pretensa liberdade individual, afim do pensamento liberal - espartilham-se em hábitos previsíveis, não ultrapassando circunscrições balizadas por parâmetros e dimensões pré-estabelecidas. Limitar-se a esses hábitos pode significar delimitação alienante à canalização de cursos monológicos, mesmo que estes venham a se erigir como efêmeras passarelas da sociedade do espetáculo, 
bem ao gosto das mídias. Uma práxis efetivamente crítica não permanecerá restrita a esses enquadramentos, alheia a laços mais amplos, que envolvam tensas relações dialógicas entre fios discursivos de diversas áreas do conhecimento. Articulações que podem levar a problemáticos nós multidiscursivos, inclinados à discussão das possíveis conexões - sempre colocadas no plural - entre o mundo que se desenha na vida cultural e suas relações com o chão das relações político-sociais.

\section{Referências Bibliográficas}

ABDALA JUNIOR, Benjamin. Fronteiras múltiplas, identidades plurais: um ensaio sobre mestiçagem e hibridismo cultural. São Paulo: SENAC, 2002. . Camões - épica e lírica. São Paulo: Scipione, 1993.

ANDRADE, Mario de; TENREIRO, Francisco José. Poesia negra de expressão portuguesa. Ed. Fac-similar organizada por Manuel Ferreira. Linda-a-Velha, África Ed., 1982. LOBO ANTUNES, António. Os cus de judas. Lisboa: Editorial Vega, 1979.

MACEDO, Hélder. Partes de Africa. Lisboa: Editorial Presença, 1991.

OBAMA, Barack. A audácia da esperansa. São Paulo: Larousse do Brasil, 2007.

PEPETELA. Mayombe. São Paulo: Ática, 1982.

RETAMAR, Roberto Fernández. Para el perfil definitivo del hombre. 2. ed. corrigida e aumentada. La Habana: Letras Cubanas, 1995.

ROSA, João Guimarães. Grande sertão: veredas. 29. ed. Rio de Janeiro: José Olympio, 1986.

SHOT, Ella; STAM, Robert. Crítica da imagem eurocêntrica. São Paulo: Cosaf Naif, 2006. 